\title{
The influence of the reducing conditions on the final microstructure and performance of nickel-yttria stabilized zirconia cermets
}

\author{
H. Monzón and M. A. Laguna-Bercero
}

Instituto de Ciencia de Materiales de Aragón, U. Zaragoza-CSIC, C/ María de Luna 3, E-50.018 Zaragoza, Spain

\begin{abstract}
Ni-YSZ (yttria stabilized zirconia) cermets are the most widespread composite materials to be used as SOFC fuel electrodes. These materials are generally fabricated by the reduction of $\mathrm{NiO}$ to $\mathrm{Ni}$ in a NiO-YSZ composite, where the reducing conditions have a great effect in the final microstructure of the electrode. In the present work, several reducing conditions were explored in order to find the most suitable microstructure for anode-supported microtubular solid oxide fuel cells (SOFCs). Samples were firstly reduced in either pure or diluted $\mathrm{H}_{2}$ (dry or humidified), at temperatures ranging from 400 to $800{ }^{\circ} \mathrm{C}$ while their DC conductivity was monitored. The highest conductivity value was measured for the sample reduced in pure humidified hydrogen at $800^{\circ} \mathrm{C}$. However, this sample experienced conductivity degradation in comparison with samples reduced under dry conditions. For the studied temperature range, nucleation of nano-porous nickel particles is firstly formed during reduction. However, from our experiments it was concluded that those nanoparticles are not stable with time, at least at temperatures between 600 ${ }^{\circ} \mathrm{C}$ and $800{ }^{\circ} \mathrm{C}$. Electrochemical characterization of complete microtubular cells under real wet conditions was also performed under current load, confirming that the microstructure of the $\mathrm{Ni}$ YSZ cermet is still evolving during operation.
\end{abstract}




\section{Introduction}

The most extended composition for solid oxide fuel cell (SOFC) anodes consists on a cermet formed by nickel, acting as catalyst for hydrogen dissociation and current collector, and YSZ (yttria stabilized zirconia) acting as ionic conductor. Although some fabrication techniques may be based on metallic nickel or nickel salts, most of them use nickel oxide as a precursor, relying on an initial exposure of the electrode to the fuel stream (reducing atmosphere) in order to conform the final electrode composition. When using hydrogen as fuel, the gas reacts with $\mathrm{NiO}$ forming metallic nickel, as shown in eq. 1. This reaction produces volume shrinkage close to $40 \%$, forming a pore network distributed between the $\mathrm{Ni}$ phase. As the actual reaction taking place during cell operation occurs in the 1D region, known as triple phase boundary (TPB, YSZNickel-pore interphase), the microstructure in this region is crucial to achieve maximum electrode performance. Furthermore, nickel phase connectivity is also critical as isolated Ni particles will not contribute towards fuel oxidation during cell operation. The final Ni-YSZ microstructure is largely determined by the initial composition of NiO-YSZ, where particle sizes and percolation thresholds should be also optimized.

$$
\mathrm{NiO}+\mathrm{H}_{2} \rightarrow \mathrm{Ni}+\mathrm{H}_{2} \mathrm{O}
$$

As elucidated in several reviews, Ni-YSZ cermet is the most used material as a SOFC fuel electrode [1-4]. However, it presents some drawbacks including those associated with thermal cycling, redox stability due to the significant volume changes upon oxidation of $\mathrm{Ni}$ to $\mathrm{NiO}$ and thus affecting the mechanical integrity of the cell, as well as sulphur deposition or coking when 
carbon rich fuel streams are used [5,6]. In recent years, several efforts are being performed in order to elucidate the redox-cycling problem [7-12].

The objective of the present study is to explore by what means the reducing conditions affect the final Ni-YSZ microstructure on a given tubular anode substrate. Although there are several works in the literature about this subject, there is no general agreement on how these parameters affect the final sample properties. Experimental characterization is possibly the most reliable procedure of elucidating how the reduction process affects each given microstructure, as described in detail in the review of Ettler et al. [13] In this trend, Pihlatie et al. [14] found that the initial electrical conductivity and the short-term conductivity loss of Ni-YSZ cermets depend closely on the operating temperature and steam content, being both processes nearly instantaneous. They also observed that there are at least two overlapping processes contributing to the change of conductivity, depending on the initial particle size distribution of $\mathrm{Ni}$ and cermet microstructure. They concluded that Ni growth can be reduced by lowering the temperature. In addition, Saraf et al. [15] reported bulk migration of $\mathrm{Ni} / \mathrm{NiO}$ in $\mathrm{Ni}-\mathrm{YSZ}$ cermets during hydrogen reduction. Lee $e t$ al. [16] also studied different Ni-YSZ reducing conditions and found that the growth of $\mathrm{Ni}$ particles occurs when increasing the temperature and humidity conditions, and thus decreasing the total and active TPB lengths. Moreover, they observed the formation of cracks on the surface, as well as in the layers of the anode at higher temperatures and humidity conditions. Studies about the effect of the reduction process on electrolyte supported SOFCs were also performed [17]. These authors also found that the anode polarization is highly affected by the reducing conditions of thin electrodes.

Regarding the temperature of reduction, it is believed that there is an increase of the conductivity by raising the temperature [18]. However, once the material has been reduced, subsequent 
treatment at high temperatures in reducing conditions does not improve conductivity values. In this sense, Jiao et al. [19] recently reported that reducing the NiO-YSZ cermet at temperatures as high as $1000{ }^{\circ} \mathrm{C}$ could be beneficial, where low degradation rates were found after 100 hours under operation, in comparison with samples reduced at lower temperatures. It seems that the reduction at $1000^{\circ} \mathrm{C}$ leads to stronger Ni-YSZ interfacial bonding.

There is general agreement in the literature $[20,21]$ about the mechanism of the reaction in eq. 1. It consists on an initial induction (i.e. nucleation) phase taking place in the surface of $\mathrm{NiO}$ particles, followed by reaction at the interface of the newly formed nickel and nickel oxide particles. This second phase proceeds auto-catalytically (metallic nickel acts as catalyst for the hydrogen dissociation) and thereby this second step shows faster kinetics.

On the other hand, nickel shows fast coarsening at common SOFC temperatures, due to high diffusive mobility. This coarsening is driven by the minimization of surface energy, and is considered an issue regarding long term operation due to the loss of the TPB length and interparticle connectivity. Those findings were also confirmed by in situ NiO-YSZ reduction using electron microscopy techniques [22,23]. On the other hand, the water effect on this mechanism is not yet fully understood. There are evidences confirming an increase in Ni mobility due to the formation of a $\mathrm{Ni}_{2}-\mathrm{OH}$ dimer complex [24]. Other authors also suggest the formation of a $\mathrm{Ni}(\mathrm{OH})_{2}$ hydroxide [25]. Additionally, the presence of water in the gas feed stream has been observed, causing an increase in the initial induction phase during reduction [21].

In the present work, we will study different reducing conditions of NiO-YSZ tubular anode supports produced via extrusion, in order to determine the most stable microstructure. Particular attention will be focus on studying this evolution by both microstructural and electrochemical analysis. 


\section{Experimental}

NiO-YSZ tubular anode supports were produced by powder extrusion moulding (PEM). For this purpose, a powder formulation based on $\mathrm{NiO}$ (GNO grade F, Hart Materials, median particle size $\mathrm{D}_{50}=0.7 \mu \mathrm{m}$ ) and YSZ (TZ-8YS, Tosoh Corporation, $\mathrm{D}_{50}=0.9 \mu \mathrm{m}$ ) was employed. Commercial corn starch was also used as pore former to increase the porosity of the anode supports. Final composition of the anode support is Ni-YSZ ratio of 50:50 (\% in volume of solid phase), with porosities near $50 \%$. Sample $\mathrm{HTD}^{*}$ was fabricated using coarser $\mathrm{NiO}$ powder (NiO grade A, INCO, $\mathrm{D}_{50}=8 \mu \mathrm{m}$ ). Final dimensions of the tubular samples are $50 \mathrm{~mm}$ in length, $2 \mathrm{~mm}$ of internal diameter and $3.2 \mathrm{~mm}$ of external diameter. Additional details about the extrusion process can be found in references [26] and [27]. Different anode supports were then cut into $5 \mathrm{~cm}$ cylinders, sintered at $1500^{\circ} \mathrm{C}$ and then reduced under different conditions. Figure 1 (left) shows a transverse-cross section of the as-sintered NiO-YSZ tube. In this SEM image, pores correspond to the black phase, NiO is the darkest grey phase and YSZ is the lighter grey phase. The only porosity observed is the one formed during the burnout of the pore former during the sintering step (corn starch, between 4 to $10 \mu \mathrm{m}$ ). The typical microstructure of a Ni-YSZ cermet after $\mathrm{NiO}$ to $\mathrm{Ni}$ reduction is shown in figure 1 (right). In all SEM images of reduced Ni-YSZ cermets, pores correspond to the black phase, YSZ is the darkest grey phase and metallic nickel is the lighter grey phase. Pores can be seen in a bi-modal distribution: large pores from the burnout of the pore former $(4-10 \mu \mathrm{m})$ and pores formed during the reduction process $(\sim 1 \mu \mathrm{m})$. All the studied reducing conditions are summarized in table 1 . During the reduction, a standard four-electrode setup was applied for the DC conductivity measurements, as shown in Fig. 2. This experiment allows an indirect measure of the evolution of the reduction reaction via the DC conductivity of 
the sample, similar to the experiment described in reference [14]. The different samples were electrically contacted using gold wire and gold paint to improve the contact. Potential probes were fixed at a distance of ca. $10 \mathrm{~mm}$. The test was performed using a Princeton Applied Research VSP potentiostat/galvanostat (resolution under $5 \mu \Omega$ ). In order to avoid the effects of electrode polarization and noise, static measurements were performed twice, passing current in opposite directions. All the measured data differed less than 5\%. The measured resistances were used to calculate the conductivity $(\sigma)$. Potentiostatic experiments were performed applying a voltage of $20 \mathrm{mV}$. The limitation of this method is that it is only useful once an initial percolating Ni phase has been established across the sample. Samples were then introduced inside an alumina tube, which was later sealed on both edges to rubber tubing in order to introduce the desired atmosphere. The alumina sample container was then placed inside an in-house tubular furnace with a homogeneous hot zone of $5 \mathrm{~cm}$ in length. Each sample was heated to the selected temperature while fed with a $\mathrm{N}_{2}$ flow of $200 \mathrm{ml} \mathrm{min}^{-1}$. Once the selected temperature was reached, the gas feed flow was switched to the one specified in table 1 for each specific test. All tests were performed without steam, except for sample named HTW. For this sample, the feed stream was passed through a bubbler at room temperature (steam content 3\%). All samples were kept under reducing conditions for 20 hours. Finally, the samples were cooled without interrupting the reducing gas flow. DC conductivity of the samples was again measured at room temperature. The final DC conductivity measurement accounts not only for the conductivity achieved during reduction, but also for the degradation due to nickel coarsening that took place under each conditions for the entire test.

Anode supported Ni-YSZ/YSZ/LSM-YSZ cells were fabricated using NiO-YSZ microtubular supports fabricated by PEM. YSZ (TZ-8YS, Tosoh) electrolytes were deposited by dip-coating and cosintered at $1500{ }^{\circ} \mathrm{C}$ for 2 hours. Two cathode suspensions were then deposited also by dip- 
coating, the first one using a 1:1 (vol\%) ratio of LSM (Fuel cell materials) and TZ-8YS (Tosoh), acting as the functional layer $(\sim 20 \mu \mathrm{m})$, and a second one using a 4:1 ratio of the same materials to enhance current collection $(\sim 15 \mu \mathrm{m})$. Both layers were sintered at $1150{ }^{\circ} \mathrm{C}$ for 1.5 hours. Final dimensions of the cells are $50 \mathrm{~mm}$ in length; wall thickness of $\sim 700 \mu \mathrm{m}$; outer diameter of 3.2 mm; electrolyte thickness of $\sim 20 \mu \mathrm{m}$; and total cathode thickness of $\sim 35 \mu \mathrm{m}$. Additional details of the fabrication process can be found in references [26] and [27]. Chronoamperometric studies and Electrochemical Impedance Spectroscopy (EIS) studies were subsequently performed.

Finally, the different samples were observed in a Merlin FE-SEM (Carl Zeiss) in order to characterize at a qualitative level the morphology of the nickel microstructure generated during the experiments. For this purpose, samples where infiltrated with epoxy resin, ground and polished. Observations were made at low accelerating voltages in order to obtain contrast between nickel and YSZ phases as described by Thydén et al. [28] and using an EsB (Energy selective Backscattered) detector. The study of the volume fraction of the different phases (nickel, YSZ and pore) by image thresholding was performed using the DigitalMicrograph (TM) 3.10.0 (Gatan Inc., USA) software. For this purpose, three different images for each sample, taken with identical magnification $(\times 5,320)$, were analyzed. Particle size was calculated using the interception method and the TPB length (expressed in $\mu \mathrm{m}^{-2}$ ) was also calculated in a similar manner as described by Faes et al. [29].

\section{Results and Discussion}

\subsection{Conductivity measurements}

Results of the potentiostatic test for the first two hours are shown in figure 3. At the initial state, all samples present zero DC conductivity as they begin with an oxidized state (NiO). After 
switching to reducing atmosphere, $\mathrm{NiO}$ reduction is initiated and DC conductivity begins to rise in most of the samples. The reduction test at $400^{\circ} \mathrm{C}$ (LTD) is the exception, where no DC conductivity was recorded during the whole duration of the test. All samples showed a summit in DC conductivity (except for the LTD sample) and then displayed a decay on conductivity over time, which can be attributed to nickel coarsening by reducing the overall Ni phase connectivity. For samples reduced in a dry atmosphere and pure hydrogen, the maximum conductivity was observed for the sample reduced at $800^{\circ} \mathrm{C}$ (HTD), but reduces rapidly to a similar value of the one recorded for the sample reduced at $600^{\circ} \mathrm{C}$ (MTD). According to the theory of contiguity described by Simwonis et al. [30], this observation would evidence that as the same initial material was used, even though kinetics differ at this two temperatures, they rapidly tend to a similar degree of connectivity. Even though the samples reduced using pure hydrogen (HTD, HTW and MTD) show a fast linear increase in DC conductivity, the sample reduced in the diluted reduction gas stream (HTD10) shows a much slower and nonlinear increase in conductivity, which is only measurable after one hour from the initial exposure to the reducing atmosphere. During this test, either an apparatus or connection failures occurred, causing periods in which no data was recorded, but without any manipulation measurement was restored after several minutes. The final conductivity of this sample was the highest recorded (see table 1). This is consistent with water accelerating the $\mathrm{Ni}$ coarsening, as these conditions are probably the ones producing water at a slower rate, while the feed gas rate was kept the same as for other tests (i.e. same rate of gas to flush produced water out of the system).

Results for the room temperature (RT) conductivity measurements after the treatment are shown in table 1, also showing a comparison between the last recorded value of DC conductivity measured in the reduction test and the value measured at room temperature (equivalently scaled to $800^{\circ} \mathrm{C}$ ). It was observed that most samples showed lower conductivity at RT. Although it 
would be reasonable to assume that $\mathrm{Ni}$ could be re-oxidized during cooling, we do believe that this is not the case as we do not observe NiO by SEM analysis after the experiments. Possibly, the loss of conductivity is most likely attributed to nickel shrinkage during cooling. It is also remarkable that the sample reduced at $600^{\circ} \mathrm{C}$ is the least conducting in the room temperature test. SEM observations for this sample revealed small gaps between nickel particles, as for the sample reduced at $400^{\circ} \mathrm{C}$. A possible explanation of this fall of conductivity could be explained if some of these gaps were closing when the sample is heated, as Ni has a higher thermal expansion coefficient than YSZ, enhancing the nickel phase connectivity at high temperatures. Apparently, the temperature during these two tests was not sufficient to cause nickel adjacent particles to sinter during the test period. The sample reduced at $400^{\circ} \mathrm{C}$ still yields no DC conductivity, associated to a poor connectivity of metallic nickel particles, and also confirmed by SEM (see next section). The highest conductivity was achieved for the HTD10 sample, followed by the HTD sample and finally the largest degradation was observed for the HTW sample, the one reduced in a humidified atmosphere. Most samples show lower conductivity values at RT, as a consequence of the loss of conductivity due to nickel shrinkage on cooling. Surprisingly, HTD sample showed a higher conductivity value at RT. This trend was observed for the samples that were not exposed to a wet gas stream. Additionally, this conductivity decay seems unimportant for samples with a lower water formation rate for the given flushing flow.

\subsection{Morphological observation}

Figure 4 shows the resulting microstructure after each test. MTD and LTD samples (figures 4.b and 4.c) present gaps surrounding nickel particles and a lesser extent of nickel coarsening, as compared to samples reduced at $800{ }^{\circ} \mathrm{C}$. Moreover, some unreacted $\mathrm{NiO}$ can be observed in the 
LTD sample. Additionally, both samples show internal porosity inside the nickel particles, though this effect is more evident in the sample reduced at $400^{\circ} \mathrm{C}$ (LTD). Small pores (nanometric range) are observable inside nickel particles in samples reduced at $800^{\circ} \mathrm{C}$ (figures 4.a, 4.d and 4.e). It is also remarkable that no $\mathrm{NiO}$ was detected for this sample, assuring a complete $\mathrm{NiO}$ to Ni reduction. These observations could be explained by $\mathrm{NiO}$ reduction taking place inside the large particles while forming a pore channel inside the particles extending from the interface formed between the newly formed $\mathrm{Ni}$ crystallites and $\mathrm{NiO}$ particles, as reported by Jeangros et al. ${ }^{19}$ Porous nickel particles are not stable surface-energy-wise, and they will tend to densify at a rate limited by nickel mobility, explaining why this phenomenon is observed to a higher extent in the lower temperature experiments.

The study of the stability of nanoporous nickel particles will be of great interest. For that purpose, we have fabricated another sample (named HTD*) using the same composition, but in this case $\mathrm{NiO}$ powder with bigger particle size $(\sim 8 \mu \mathrm{m})$ was used. This sample was reduced under dry hydrogen at $800{ }^{\circ} \mathrm{C}$ for 30 minutes, and the microstructure of the sample subsequently cooled after reduction is shown in figure 4.f. As observed in the figure, this reducing conditions and microstructure are optimal to obtain nanoporous Ni particles. Image analysis revealed that those nanopores present a diameter of $220 \pm 90 \mathrm{~nm}$. However, from our experiments it was concluded that those nanoparticles are not stable with time, at least at temperatures between $600{ }^{\circ} \mathrm{C}$ and 800 ${ }^{\circ} \mathrm{C}$. At these temperatures, internal nanopores of the Ni particles collapse forming dense nickel particles, as a consequence of well-known Ostwald Ripening mechanism. This mechanism is highly influenced by the temperature and the reducing conditions, as discussed in the introduction section. For those reasons they are probably not practical at least for conventional SOFC applications. However, although this is out of the scope of the present study, it should be interesting to further investigate the f stability of these nanoporous nickel particles under different 
conditions under $600{ }^{\circ} \mathrm{C}$, as we believe that those nanoparticles could present a huge range of potential applications for different catalytic processes.

On the other hand, samples reduced with pure hydrogen at $800^{\circ} \mathrm{C}$, with and without added humidity, showed very similar microstructures. However, the RT DC-conductivity measure points out that a higher loss of connectivity took place for the HTW sample. In contrast with the gaps seen in the samples reduced at low temperature, no gap exists in most Ni-YSZ interfaces. At higher temperatures, YSZ becomes a good oxygen ion conductor and $\mathrm{NiO}$ reduction could take place through the NiO-YSZ interface [22, 31, 32]. A lesser amount of nickel coarsening can be seen in the sample reduced in the diluted hydrogen flow when compared to the one reduced with the $800^{\circ} \mathrm{C}$ dry stream.

Finally, image analysis was also performed in order to determine the volume fraction, particle sizes and TPB length per unit surface area. A summary of the different phase fractions, particle sizes and TPB lengths can be found in table 2. Phase fraction values for each sample are in concordance with the theoretical values. TPB length values are in good agreement with values reported by other authors $\left(0.7-5.2 \mu \mathrm{m}^{-2}\right)$ for cermets containing particles of similar sizes [29, 33, 34, 35], especially taking into account that these anode supported samples are formed with added porosity (in the range of $10 \mu \mathrm{m}$ ) to improve gas diffusion throughout the support of the microtubular cells. HTW and HTD10 samples present higher TPB length values, in concordance with their enhanced conductivity (see table 1). Finally, from particle size analysis we observed that YSZ particle sizes remained constant for all samples, as expected. However, significant differences were obtained for nickel particle sizes. The smallest nickel particles are those from the MTD sample, consistent with the lower ageing temperature. However, we should expect an increase of the TPB length for this sample that we do not observe. The reason for this finding is 
probably due to the observed gaps between nickel and YSZ particles, as a consequence of the slower reduction kinetics.

\subsection{Evolution of the Ni-YSZ cermet after $\mathrm{NiO}$ reduction}

The initial hours of operation of a Ni-YSZ anode are also of great importance, as the microstructure, especially $\mathrm{Ni}$ particles, could not have reached an equilibrium state. Nickel coarsening is one of the major concerns of Ni-YSZ anodes [36, 37]. For this purpose, we have performed a chronoamperometric study of microtubular single cells at $800{ }^{\circ} \mathrm{C}$ and a voltage of $0.8 \mathrm{~V}$, as shown in figure 5 . Fuel composition at the anode side was fixed at $90 \mathrm{ml} \mathrm{min}^{-1}\left(97 \% \mathrm{H}_{2}\right.$ and $3 \% \mathrm{H}_{2} \mathrm{O}$ ). Those results are shown in figure for both HTW and MTW samples during a period of 70 hours. It is observed that for the HTW sample (reduced at $800{ }^{\circ} \mathrm{C}$ ), there is a noticeable evolution during the first 15 hours, and then current density stabilizes at about $400 \mathrm{~mA}$ $\mathrm{cm}^{-2}$. However, for the MTW sample (reduced at $600{ }^{\circ} \mathrm{C}$ ), this stabilization period is much longer, as current density values are stabilized after 60 hours under current load. SEM experiments before and after the chronoamperometric study confirmed that both YSZ electrolyte and LSMYSZ remains unaltered, as seen in figure 6. However, the anode presents an evolution by coarsening of nanosized nickel particles at the Ni-YSZ electrode, which is currently being under study under longer operation times. This evolution process was also studied by EIS experiments, as observed in figure 7 for HTW and MTW samples. For the HTW sample, most of the change in this study takes places during the initial 17 hours. During this period, there is a decrease of the low frequency process, taking place at $\sim 2 \mathrm{~Hz}$, whereas the high frequency process $(\sim 1 \mathrm{kHz})$ was increased. Based on measurements as a function of $\mathrm{pH}_{2}$, both processes are mainly influenced by the anode. It is then reasonable to assume that the coarsening leads to bigger pores facilitating gas 
diffusion (decrease of the low frequency process) but at the same time, the TPB length is reduced and thus the catalytic activity of the anode was also decreased (increase of the high frequency component). After this initial period of 17 hours, a similar trend was observed, although this evolution is less severe, and those minor fluctuations could be also related with small changes in fuel and/or cell temperature. An analogous effect was observed for the MTW sample, although in this case the evolution is slower, as also observed in the chronoamperometric study.

\section{Conclusions}

A wide range of different microstructures can be formed from the same starting material. Even a non-conducting material was formed during the lower temperature experiment. Not only the reduction mechanism and kinetics play a role in the final morphology, but also the nickel species mobility. The experiments described in this study support the hypothesis of nickel mobility being enhanced by the presence of steam. The mentioned species mobility also play a role in the $\mathrm{NiO}$ reduction kinetic behaviour, but further experiments are required to elucidate the nature of this interaction. The difference observed between DC conductivities in the high and room temperature tests on the sample reduced at $600^{\circ} \mathrm{C}$ evidence that there is a difference in the effective microstructure between both temperatures. In order to fully understand those effects, electrochemical characterization under the working conditions seems to be the most reliable method and will be performed in a future work. Regarding exclusively DC conductivity at the end of the test, the best performance was obtained for the sample reduced in a diluted hydrogen atmosphere. 
As a general conclusion, the reducing conditions of a Ni-YSZ cermet are crucial for its performance as a SOFC anode especially during the first hours of operation, as their properties can drastically change during this period. Those conditions are hardly dependent on the microstructure of the Ni-YSZ cermet. For this reason, it is hard to validate most of the literature data for comparison purposes. Preconditioning of Ni-YSZ anodes until reaching a steady-state microstructure would be desirable.

\section{Acknowledgments}

Authors would like to thank the project MAT2015-68078-R, financed by the Spanish Government (Ministerio de Economía y Competitividad) and the Feder program of the European Union. Authors would also acknowledge the use of Servicio General de Apoyo a la Investigación-SAI, Universidad de Zaragoza. 
Table 1. Final DC-conductivities for the samples performed at room temperature and comparison with the equivalent conductivity at room temperature (estimating a linear change in nickel conductivity), measured from the last recorded point in the reduction test before contact failure or the end of the test. The different test conditions for the reduction experiments are also shown.

\begin{tabular}{|c|c|c|c|c|c|c|c|}
\hline Sample & $\mathbf{T}\left({ }^{\circ} \mathrm{C}\right)$ & 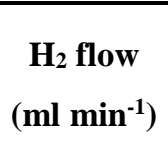 & 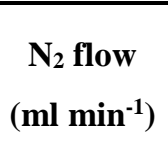 & $\begin{array}{c}\text { Humidified } \\
\text { (RT) }\end{array}$ & $\begin{array}{c}\sigma_{\mathrm{RT}} \\
\left(\mathrm{S} \mathrm{cm}^{-1}\right)\end{array}$ & $\begin{array}{c}\sigma \mathrm{RT} \text { from } \\
\text { last recorded } \\
\text { point }\left(\mathrm{S} \mathrm{cm}^{-1}\right)\end{array}$ & $\begin{array}{l}\text { from last } \\
\text { recorded } \\
\text { point (min) }\end{array}$ \\
\hline HTD & 800 & 90 & 0 & NO & $9760 \pm 490$ & $9100 \pm 490$ & 757 \\
\hline MTD & 600 & 90 & 0 & NO & $5530 \pm 270$ & $8700 \pm 430$ & 1200 \\
\hline LTD & 400 & 90 & 0 & $\mathrm{NO}$ & 0 & 0 & - \\
\hline HTW & 800 & 90 & 0 & YES & $7140 \pm 350$ & $10630 \pm 530$ & 185 \\
\hline HTD10 & 800 & 9 & 81 & NO & $10050 \pm 500$ & $10670 \pm 530$ & 1200 \\
\hline
\end{tabular}

Table 2. Summary of the image analysis performed for the different samples. As the LTD sample was not fully reduced, the analysis was not performed for this sample.

\begin{tabular}{|c|c|c|c|c|}
\hline \multirow{2}{*}{ Sample } & HTD & MTD & HTW & HTD10 \\
\hline \multicolumn{5}{|c|}{ Phase fraction (vol\%) } \\
\hline Pore & $47.8 \pm 2.3$ & $49.5 \pm 2.5$ & $49.0 \pm 2.0$ & $47.8 \pm 2.3$ \\
\hline YSZ & $25.7 \pm 1.8$ & $24.6 \pm 2.0$ & $25.1 \pm 1.9$ & $25.7 \pm 1.8$ \\
\hline Ni & $26.5 \pm 1.9$ & $25.9 \pm 2.0$ & $25.9 \pm 1.8$ & $26.5 \pm 1.9$ \\
\hline \multicolumn{5}{|c|}{ Particle size (medium diameter, $\boldsymbol{\mu m})$} \\
\hline Pore & $10.4 \pm 3.0$ & $9.0 \pm 4.9$ & $9.6 \pm 4.7$ & $7.8 \pm 2.8$ \\
\hline YSZ & $1.1 \pm 0.9$ & $0.7 \pm 0.6$ & $1.0 \pm 0.8$ & $1.2 \pm 0.8$ \\
\hline Ni & $0.9 \pm 0.8$ & $1.0 \pm 0.8$ & $0.9 \pm 0.6$ & $0.8 \pm 0.7$ \\
\hline \multicolumn{5}{|c|}{ TPB length $\left(\boldsymbol{\mu m ^ { - 2 }}\right)$} \\
\hline- & $0.7 \pm 2.3$ & $2.8 \pm 1.9$ & $3.2 \pm 1.7$ & $3.1 \pm 1.9$ \\
\hline
\end{tabular}




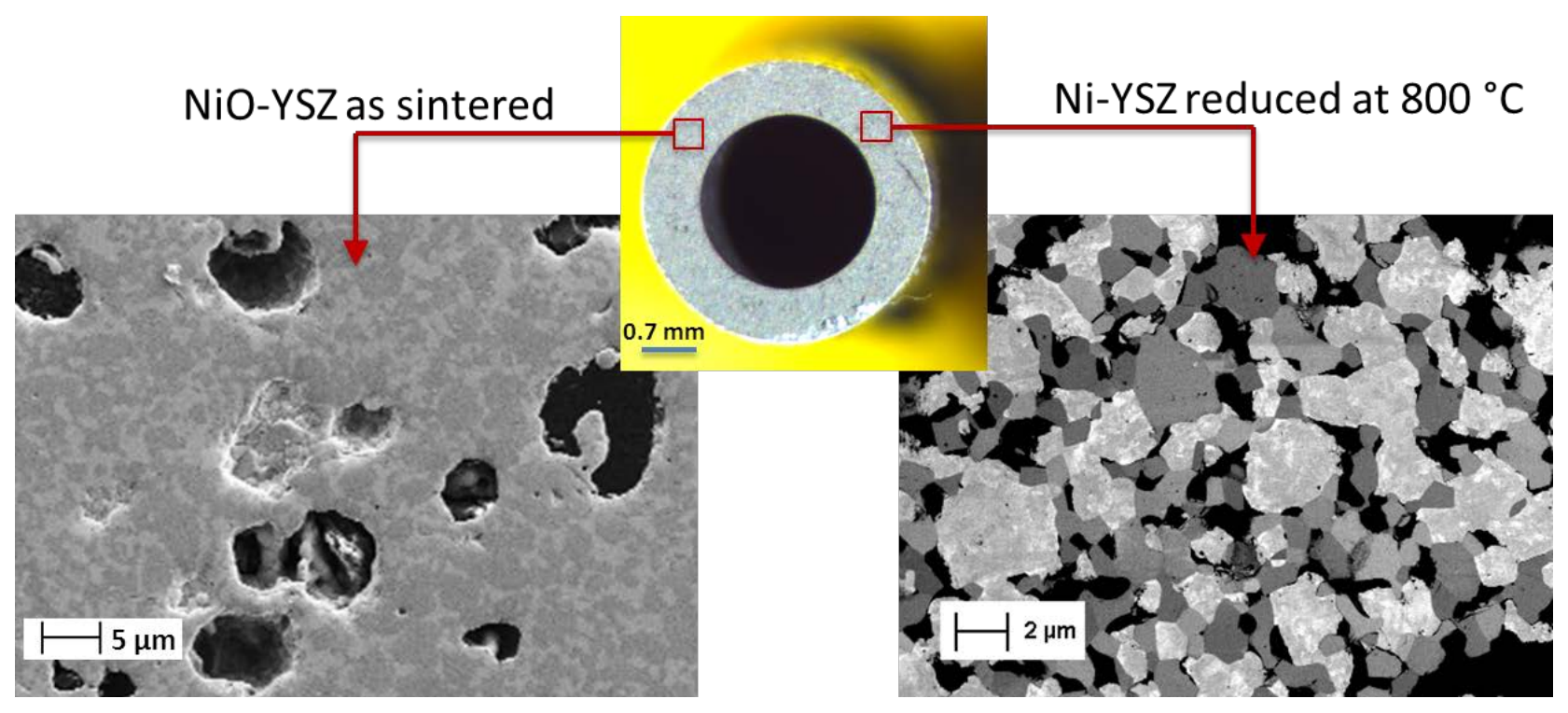

Figure 1. (centre) Transverse-cross section of a NiO-YSZ extruded tube; (left) microstructure of the NiO-YSZ as sintered; and (right) microstructure of the Ni-YSZ anode after NiO reduction. 


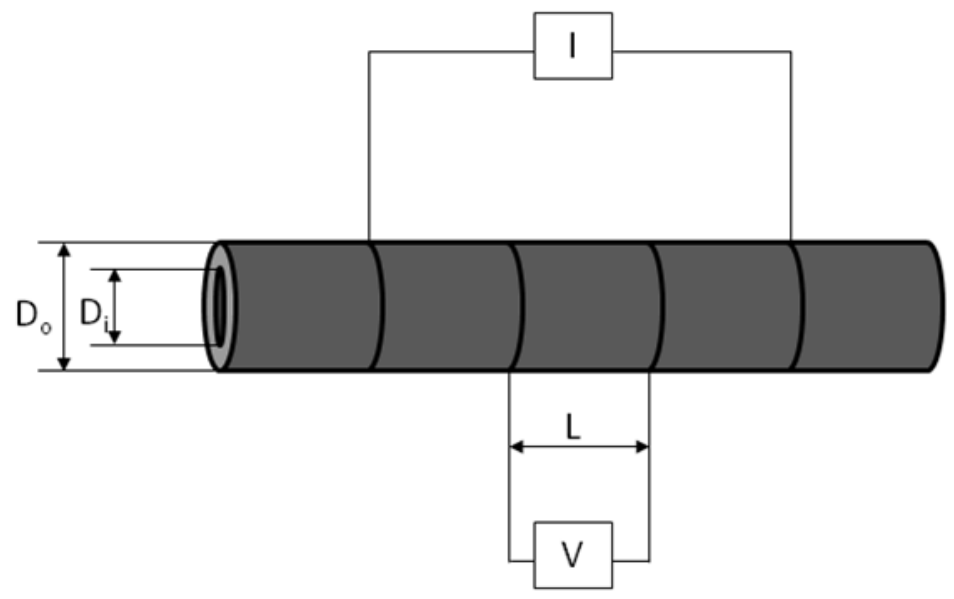

Figure 2. Experimental setup for DC current measurements on tubular NiO-YSZ samples. 


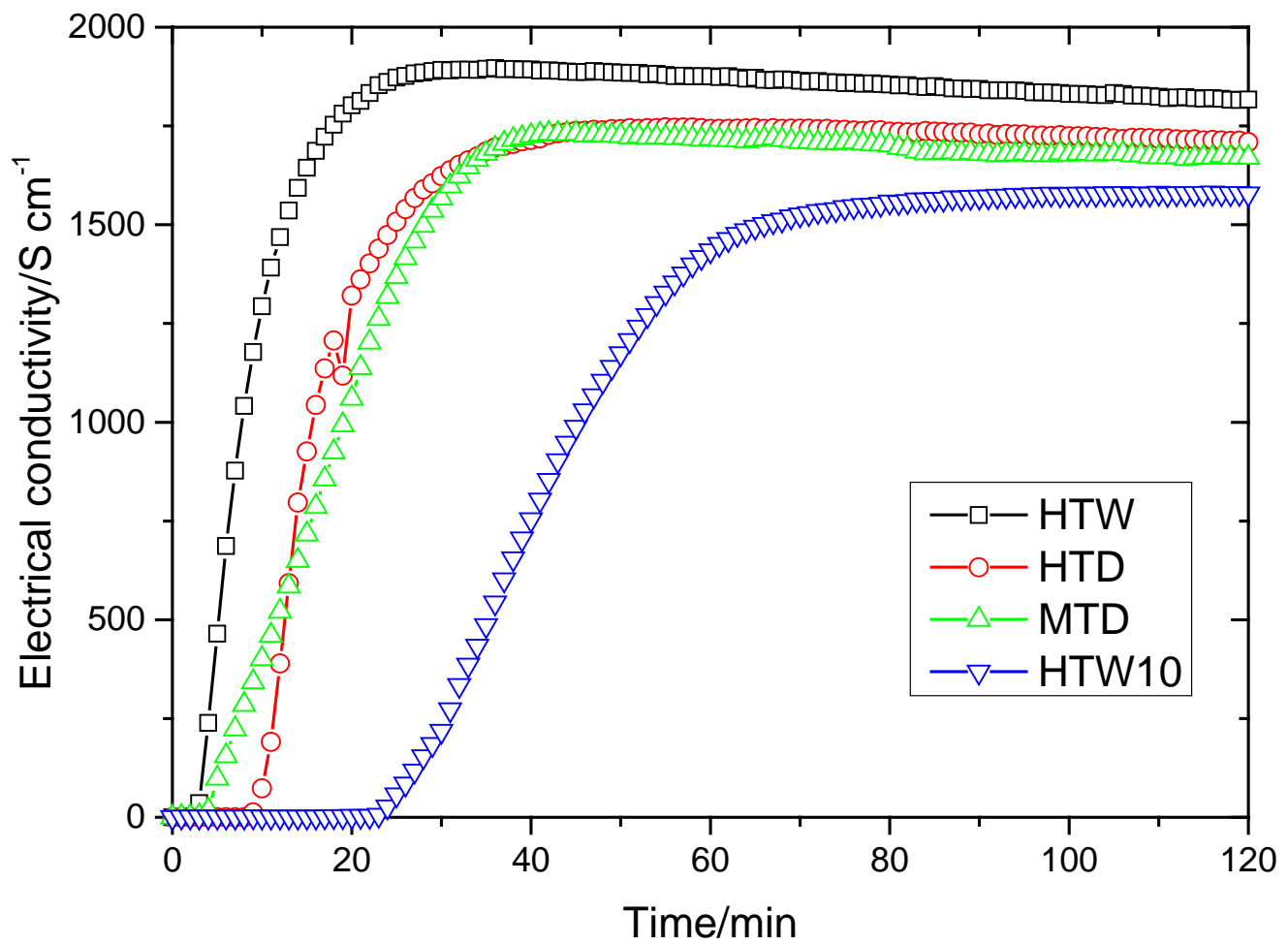

Figure 3. Initial 120 minutes of DC-conductivity test during reduction. Sample LTD is not shown in the graph as the recorded conductivity value was zero for the whole experiment. 

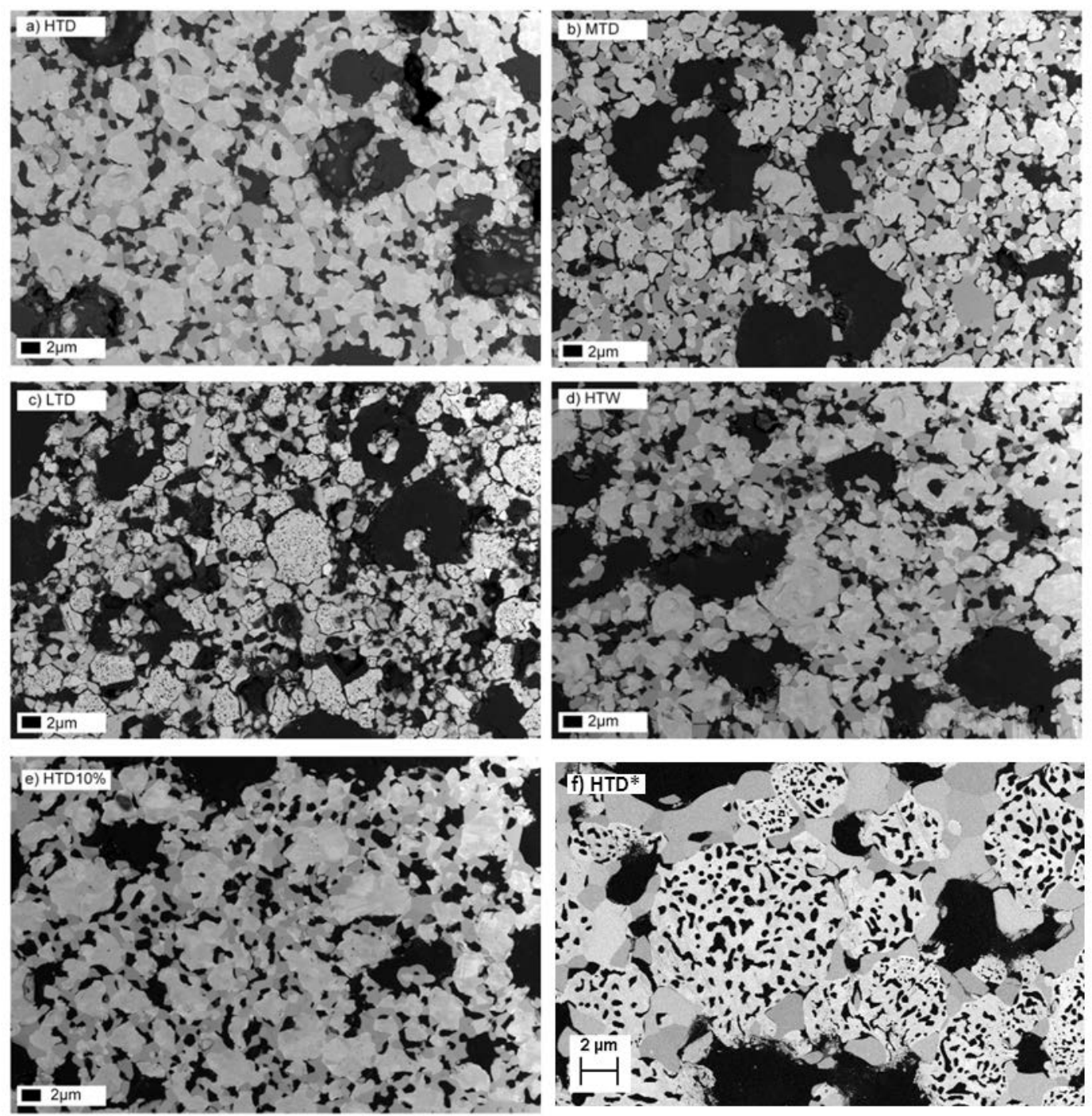

Figure 4. SEM micrographs of the resulting microstructures after the 20h reduction test for the HTD (a), MTD (b), LTD (c), HTW (d) and HTD10\% (e) samples. Image (f) corresponds to another sample reduced under dry hydrogen at $800{ }^{\circ} \mathrm{C}$, and subsequently cooled after reduction for $30 \mathrm{~min}$. 


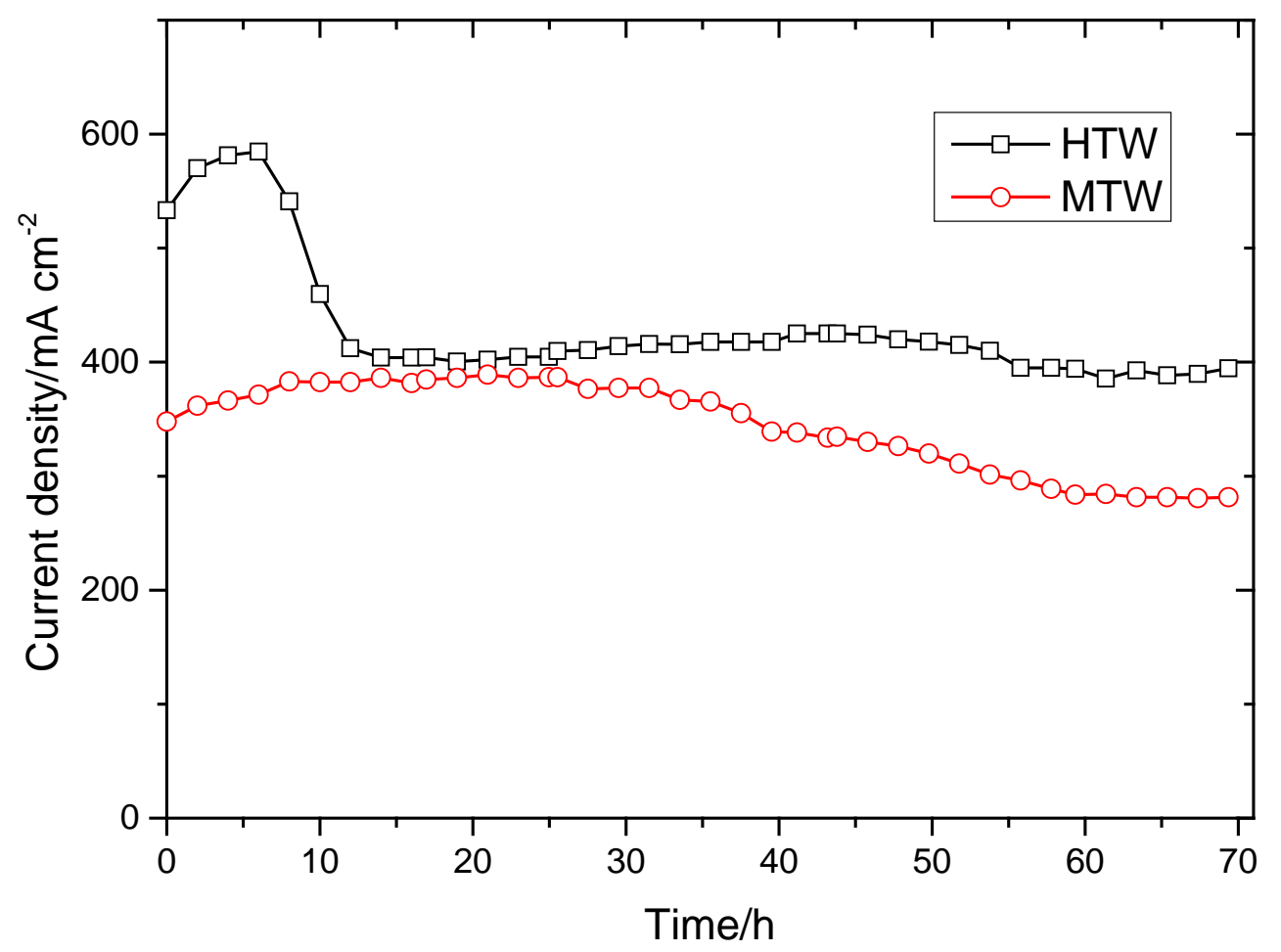

Figure 5. Chronoamperometric study at $800{ }^{\circ} \mathrm{C}$ for the HTW sample (black) and MTW sample (red) at a voltage of $0.8 \mathrm{~V}$. 


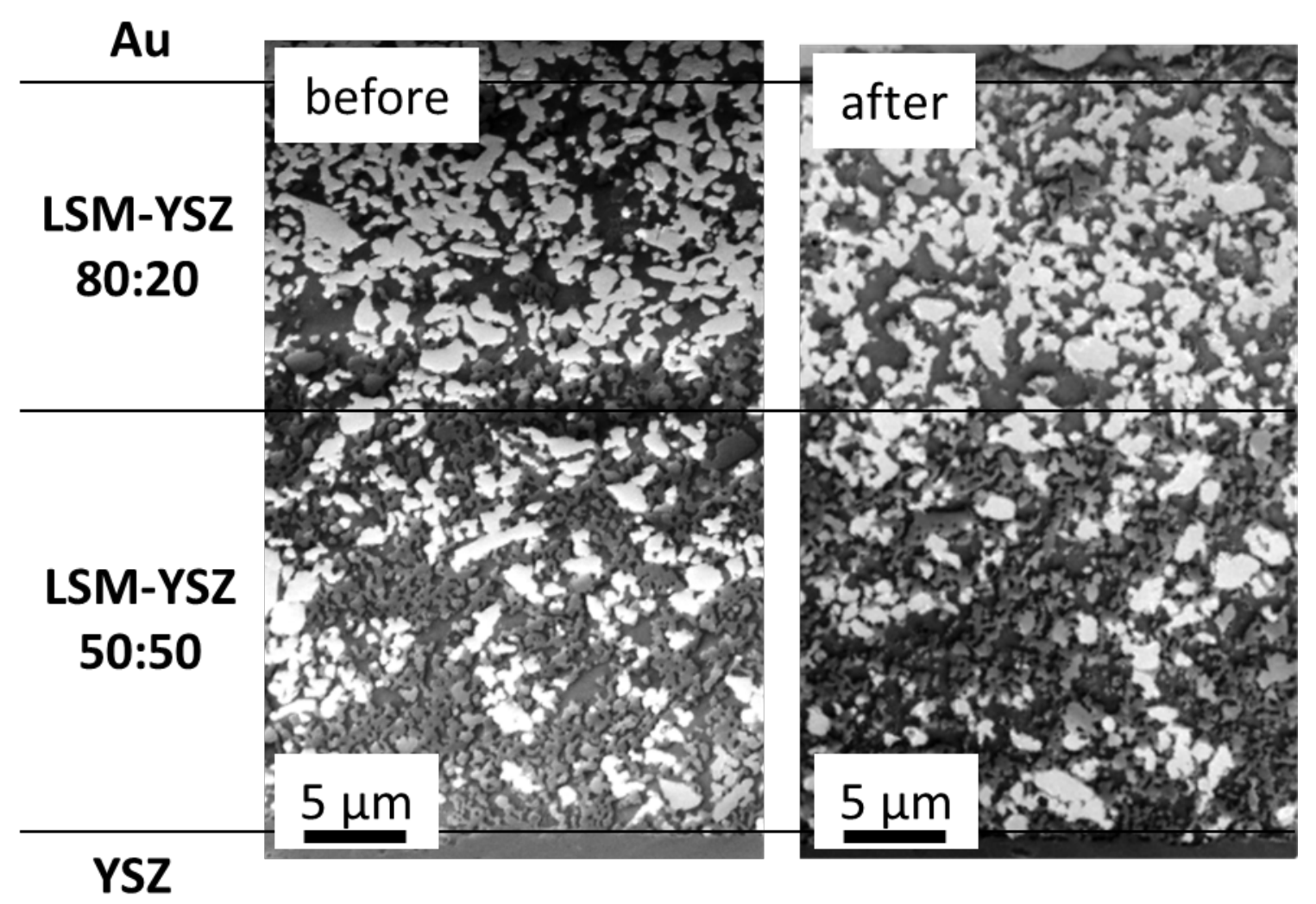

Figure 6. Microstructure of the LSM-YSZ electrode for the HTW sample before and after the chronoamperometric study. 

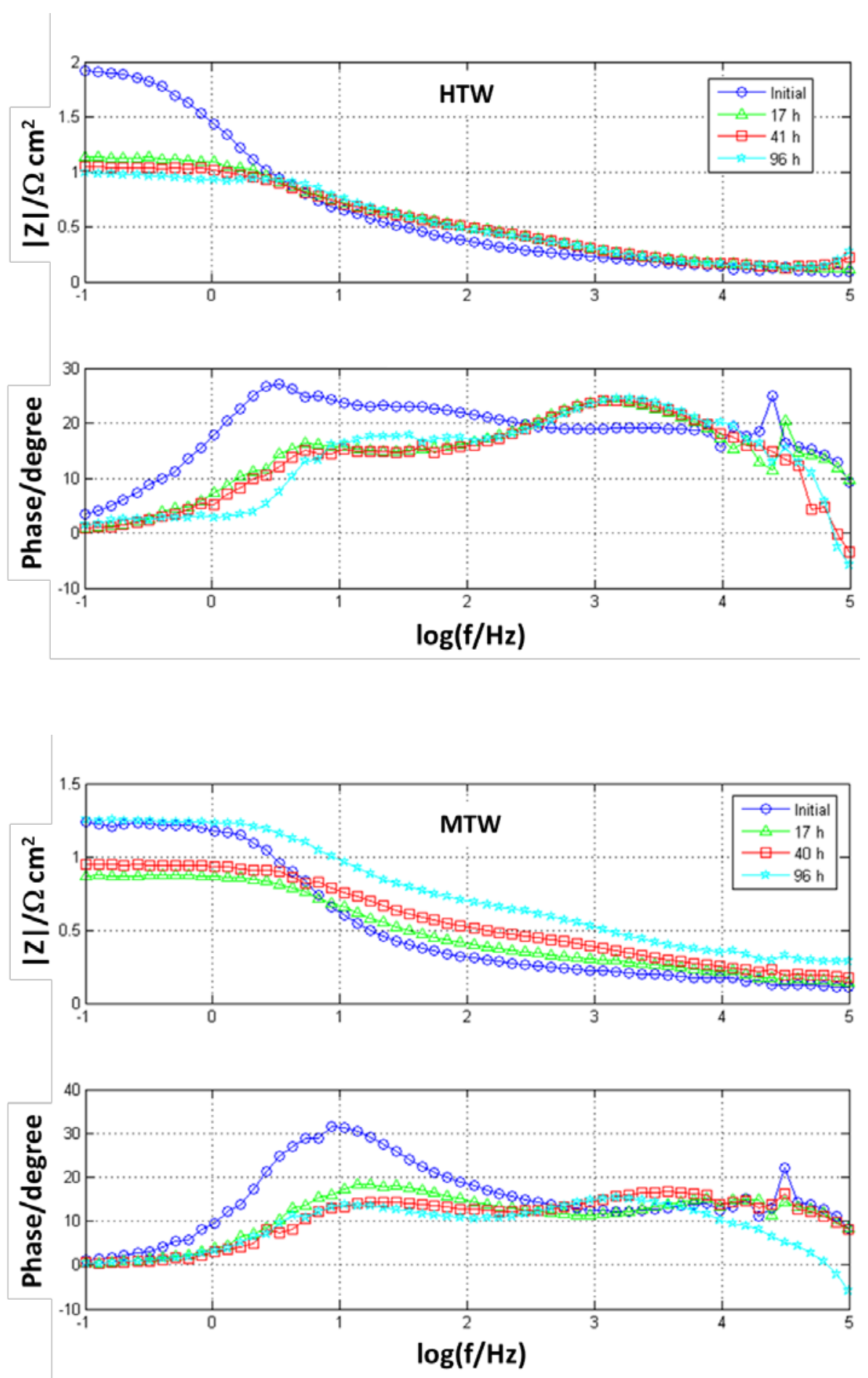

Figure 7. EIS experiments as a function of time for samples HTW (up) and MTW (down). 


\section{References}

1. A. Atkinson, S. Barnett, R. J. Gorte, J. T. S. Irvine, A. J. McEvoy, M. Mogensen, S. C. Singhal and J. Vohs, Advanced anodes for high-temperature fuel cells, Nature Materials 3 (2004) 17-27.

2. C. Sun and U. Stimming, Recent anode advances in solid oxide fuel cells, Journal of Power Sources 171 (2007) 247-260.

3. P. I. Cowin, C. T. G. Petit, R. Lan, J. T. S. Irvine and S. Tao, Recent progress in the development of anode materials for solid oxide fuel cells, Advanced Energy Materials 1 (2011) 314-332.

4. W. H. Kan, V. Thangadurai, Challenges and prospects of anodes for solid oxide fuel cells (SOFCs), Ionics 21 (2015) 301-318.

5. Z. Cheng, J.-H. Wang, Y. Choi, L. Yang, M. C. Lin and M. Liu, From Ni-YSZ to sulfurtolerant anode materials for SOFCs: electrochemical behavior, in situ characterization, modeling, and future perspectives, Energy Environmental Science 4 (2011) 4380-4409.

6. S. J. Skinner and M. A. Laguna-Bercero, Advanced Inorganic Materials for Solid Oxide Fuel Cells in Energy Materials, Duncan W. Bruce, R. Walton, and D. O’Hare, Editors, p. 39, Wiley-VCH Verlag GmbH \& Co. KGaA, Weinheim (2011).

7. A. Hagen, H. F. Poulsen, T. Klemensø, R. V. Martins, V. Honkimäki, T. Buslaps and R. Feidenshans, A Depth-Resolved In-Situ Study of the Reduction and Oxidation of Ni-Based Anodes in Solid Oxide Fuel Cells, Fuel Cells 6 (2006) 361-366.

8. D. Sarantaridis, R. J. Chater and A. Atkinson, Changes in Physical and Mechanical Properties of SOFC Ni-YSZ Composites Caused by Redox Cycling, Journal of the Electrochemical Society 155 (2008) B467-B472. 
9. A. Faes, A. Nakajo, A. Hessler-Wyser, D. Dubois, A. Brisse, S. Modena and J. Van herle, RedOx study of anode-supported solid oxide fuel cell, Journal of Power Sources 193 (2009) 55-64.

10. M. Pihlatie, T. Ramos and A. Kaiser, Testing and improving the redox stability of Ni-based solid oxide fuel cells, Journal of Power Sources 193 (2009) 322-330.

11. H. Monzón, M. A. Laguna-Bercero, Redox-cycling studies of anode-supported microtubular solid oxide fuel cells, International Journal of Hydrogen Energy 37 (2012) 7262-7270.

12. D. E. Vladikova, Z. B. Stoynov, Z. Wuillemin, D. Montinaro, P. Piccardo, I. Genova and M. Rolland, Impedance Studies of the Reduction Process in NiO-YSZ SOFC Anodes ECS Transactions 68 (2015) 1161-1168.

13. M. Ettler, H. Timmermann, J. Malzbender, A. Weber and N. H. Menzler, Durability of Ni anodes during reoxidation cycles, Journal of Power Sources 195 (2010) 5452-5467.

14. M. H. Pihlatie, A. Kaiser and M. B. Mogensen, Electrical conductivity of Ni-YSZ composites: Degradation due to Ni particle growth, Solid State Ionics 189 (2011) 82-90.

15. L. V. Saraf, D. R. Baer, A. S. Lea, Z. H. Zhu, J. J. Strohm, S. D. Sitzman and D. L. King, Bulk Migration of $\mathrm{Ni} / \mathrm{NiO}$ in Ni-YSZ during Reducing Conditions, Journal of the Electrochemical Society 157 (2010) B463-B469.

16. Y.-H. Lee, H. Muroyama, T. Matsui and K. Eguchi, Degradation of nickel-yttria-stabilized zirconia anode in solid oxide fuel cells under changing temperature and humidity conditions, Journal of Power Sources 262 (2014) 451-456.

17. S. W. Cheng, C. H. Tsai, S. H. Wu, C. K. Liu, Y. N. Cheng and R. Y. Lee, Effects of reduction process on the electrochemical and microstructural properties for electrolytesupported SOFC, International Journal of Hydrogen Energy 40 (2015) 1534-1540. 
18. L. Grahl-Madsen, P. H. Larsen, N. Bonanos, J. Engell and S. Linderoth, Mechanical strength and electrical conductivity of Ni-YSZ cermets fabricated by viscous processing, Journal of Materials Science 41 (2006) 1097-1107.

19. Z. Jiao and N. Shikazono, Quantitative Study on the Correlation between Solid Oxide Fuel Cell Ni-YSZ Composite Anode Performance and Reduction Temperature Based on ThreeDimensional Reconstruction, Journal of the Electrochemical Society 162 (2015) F571-F578.

20. J. T. Richardson, R. Scates and M. V. Twigg, X-ray diffraction study of nickel oxide reduction by hydrogen, Applied Catalysis A: General 246 (2003) 137-150.

21. A. F. Benton and P. H. Emmett, The reduction of nickelous and ferritic oxides by hydrogen, Journal of the American Chemical Society 46 (1924) 2728-2737.

22. Q. Jeangros, A. Faes, J. B. Wagner, T. W. Hansen, U. Aschauer, J. Van herle, A. HesslerWyser and R. E. Dunin-Borkowski, In situ redox cycle of a nickel-YSZ fuel cell anode in an environmental transmission electron microscope, Acta Materialia 58 (2010) 4578-4589.

23. J. Basu and R. Divakar, In-situ electron microscopy investigation of reduction-induced microstructural changes in NiO, Ceramics International 41 (2015) 12658-12667.

24. J. Sehested, J. A.P. Gelten, I. N. Remediakis, H. Bengaard and J. K. Nørskovet, Sintering of nickel steam-reforming catalysts: effects of temperature and steam and hydrogen pressures, Journal of Catalysis 223 (2004) 432-443.

25. R. Knibbe, A. Hauch, J. Hjelm, S. D. Ebbesen, and M. Mogensen, Durability of solid oxide cells, Green 1 (2011)141-169.

26. H. Monzón, M. A. Laguna-Bercero, A. Larrea, B. I. Arias, A. Várez, B. Levenfeld, Design of industrially scalable microtubular solid oxide fuel cells based on an extruded support, International Journal of Hydrogen Energy 39 (2014) 5470-5476. 
27. B. Arias-Serrano, M.E. Sotomayor, A. Varez, B. Levenfeld, H. Monzon, M. A. LagunaBercero and A. Larrea, High-performance Ni-YSZ thin-walled microtubes for anodesupported solid oxide fuel cells obtained by powder extrusion moulding, RSC Advances 6 (2016) 19007-19015.

28. K. Thydén, Y.L. Liu and J.B. Bilde-Sørensen, Microstructural characterization of SOFC NiYSZ anode composites by low-voltage scanning electron microscopy, Solid State Ionics 178 (2008) 1984-1989.

29. A. Faes, A. Hessler-Wyser, D. Presvytes, C. G. Vayenas, J. Van herle, Nickel-Zirconia Anode Degradation and Triple Phase Boundary Quantification from Microstructural Analysis, Fuel Cells 9 (2009) 841-851.

30. D. Simwonis, F. Tietz and D. Stöver, Nickel coarsening in annealed Ni/8YSZ anode substrates for solid oxide fuel cells, Solid State Ionics 132 (2000) 241-251.

31. E. C. Dickey, V. P. Dravid, P. D. Nellist, D. J. Wallis, S. J. Pennycook and A. Revcolevschi, Structure and Bonding at Ni-ZrO2(cubic) Interfaces Formed by the Reduction of a NiOZrO2(cubic) Composite, Microscopy and Microanalysis 3 (1997) 443-450.

32. M. A. Laguna-Bercero, A. Larrea, YSZ-Induced Crystallographic Reorinetation of Ni Particles in Ni-YSZ Cermets, Journal of the American Ceramic Society 90 (2007) 29542960.

33. J. R. Wilson, W. Kobsiriphat, R. Mendoza, H. Y. Chen, J. M. Hiller, D. J. Miller, K. Thornton, P. W. Voorhees, S. B. Adler, S. A. Barnett, Three-dimensional reconstruction of a solid-oxide fuel-cell anode , Nature Materials 5 (2006) 541-544.

34. B. Kenney, M. Valdmanis C. Baker, J.G. Pharoah, K. Karan, Computation of TPB length, surface area and pore size from numerical reconstruction of composite solid oxide fuel cell electrodes, Journal of Power Sources 189 (2009) 1051-1059. 
35. K. Miyawaki, M. Kishimoto, H. Iwai, M. Saito,H. Yoshida, Comprehensive understanding of the active thickness in solid oxide fuel cell anodes using experimental, numerical and semianalytical approach, Journal of Power Sources 267 (2014) 503-514.

36. H. Yokokawa, H. Tu, B. Iwanschitz and A. Mai, Fundamental mechanisms limiting solid oxide fuel cell durability, Journal of Power Sources (2008) 182, 400-412.

37. L. Holzer, B. Iwanschitz, Th. Hocker, B. Münch, M. Prestat, D. Wiedenmann, U. Vogt, P. Holtappels, J. Sfeir, A. Mai and Th. Graule, Microstructure degradation of cermet anodes for solid oxide fuel cells: Quantification of nickel grain growth in dry and in humid atmospheres, Journal of Power Sources 196 (2011) 1279-1294. 